\title{
EL DOMICILIO DE LAS PERSONAS JURÍDICAS SIN FINES DE LUCRO
}

\author{
THE REGISTERED OFFICE OF NON-PROFIT LEGAL ENTITIES
}

\author{
Mario Romero Antola 1 \\ Universidad Femenina del Sagrado Corazón. \\ Lima-Perú. \\ https://orcid.org/0000-0002-1854-7878 \\ mromeroa@unife.edu.pe
}

\section{RESUMEN}

El presente artículo versa sobre el domicilio de la persona jurídica sin fines de lucro regulado por el código civil peruano. Busca desde una perspectiva doctrinaria y jurisprudencial hacer un análisis de las disposiciones que al respecto tiene el código civil, en especial su concepto de domicilio y sede y obligatoriedad, poniendo de relieve las deficiencia y contradicciones de nuestra legislación.

\section{PALABRAS CLAVES}

Domicilio, dirección domiciliaria, sede social, asociación, fundación, comité, persona jurídica, persona jurídica sin fines de lucro.

\section{ABSTRACT}

This paper covers the topic of registered offices of the non-profit legal entities governed by the Peruvian Civil Code. Its purpose is to analyze, from academic and case law perspectives, the provisions that the civil code has established in this regard, especially on the concept of registered office, principal office, and binding force, highlighting the deficiencies and contradictions of our legislation.

\section{KEYWORDS}

Registered office, address, principal office, association, foundation, committee, legal entity, non-profit legal entity.

\section{INTRODUCCIÓN}

El presente artículo tiene como objeto tratar el tema del domicilio de las personas jurídicas sin fines de lucro reguladas en el código civil peruano de 1984, más específicamente, la asociación, la fundación y el comité. Por este motivo, cuando mencionemos a las personas jurídicas, nos estaremos refiriendo principalmente a aquellas que no tienen fines de lucro, es decir, aquellas en que los miembros no tienen derecho al patrimonio de ellas durante la vigencia de las mismas o luego de su liquidación, así como tampoco tienen participación alguna en los excedentes o ganancias que pudiera tener en el desempeño de sus actividades.

1 Abogado por la Pontificia Universidad Católica del Perú. Magister en Derecho de Familia en la Universidad Femenina del Sagrado Corazón. Docente en la Facultad de Derecho de la UNIFÉ y Decano de la Facultad de Derecho de la Universidad Femenina del Sagrado Corazón. 
Junto al nombre y la nacionalidad el domicilio es un atributo fundamental de la persona en general y de la jurídica en particular. El Derecho positivo atribuye a la persona ciertas cualidades o propiedades que se consideran inherentes a ella que se denominan atributos. Treviño (2002), citando a Rafael de Pina precisa de los atributos:

Las cualidades o propiedades de un ser constituyen sus tributos. Son aquellos elementos propios y características que encontramos en todas las personas y que tienen ciertas consecuencias jurídicas. (p.45)

Domínguez (2009) refiriéndose a los atributos de la persona refiere:

Existen ciertas cualidades que tiene toda persona por su sola condición de tal y a nivel jurídico permiten su individualización y diferenciación. Ello corresponde a la noción de "atributo". No bastará así para constituir un atributo desde el punto de vista jurídico con lo que posea toda persona, porque ello coincide con otros institutos como los "derechos de la personalidad", sino que representan la necesaria particularidad de lograr la precisión, distinción, diferenciación o individualización del sujeto en una situación o relación jurídica (p.203).

Añade: "la persona también puede ser distinguida por un elemento de individualización territorial o espacial, a saber, la sede de la persona jurídica..." (p.213)

Cifuentes (1991) define los atributos como: "las propiedades o cualidades del ser jurídico, por medio de las cuales el sujeto-persona- puede individualizarse y formar parte de la relación de derecho" (p.105)

El domicilio de las personas jurídicas sin fines de lucro no ha sido regulado clara ni exhaustivamente en la legislación civil nacional. Solamente encontramos una referencia especial a él en el código civil peruano vigente de 1984, en el caso de asociaciones en su artículo 82, de fundaciones en el 101 y de comités en el 113; otras de carácter procesal en los artículos 85 y 92, adicionalmente los artículos 98, 109 y 110 en la que más que domicilio se refiere a sede, el artículo 122 en donde tangencialmente el código se refiere a "lugar" y finalmente el artículo 129 en donde se refiere a "distrito judicial". Esta diversidad de denominaciones y la falta de definición de lo que es el domicilio, no sucede con el de la persona natural e inclusive con el de las llamadas sociedades, las que tienen una regulación, que, aunque tampoco es mayormente detallada, es algo más completa, por lo que parece necesario hacer un análisis, en lo que se refiere a las personas jurídicas sin fines de lucro, respecto de qué se entiende por domicilio, cómo se constituye, sus características, clases o tipos y utilidad, a fin de aclarar doctrinariamente lo que la legislación no ha considerado pertinente desarrollar.

Lo que resulta claro es que es de interés del derecho que, de la misma forma que las personas físicas, las personas jurídicas, deban fijar un domicilio, en el entendido que al no tener corporeidad la fijación de este es indispensable para su identificación y ubicación en un espacio determinado.

La jurisprudencia argentina, a través de la Cámara Nacional de Apelaciones en lo comercial, en el denominado pleno "quilpe" (31/03/1977) -AR/JUR/1613/1977-precisa la necesaria designación del domicilio en el caso de personas jurídicas estableciendo: 
La persona individual no requiere indicar su domicilio, porque posee corporeidad. La persona jurídica -herramienta delicadísima que la ley pone al servicio del administrado, para ser usada conforme con reglas de convivencia- carece de corporización. Esto hace imperativo que ponga a disposición de terceros un modo cierto y sencillo de localizarla y también de emplazarla.

\section{EL DOMICILIO, DEFINICIÓN, OBLIGATORIEDAD, NORMATIVA CIVIL Y COMERCIAL.}

Como cuestión preliminar debemos precisar que la palabra domicilio provendría de domicilius que a decir de algunos procede de la palabra domus(casa) y colere (cultivar habitar), más el sufijo io (resultado) por lo que domicilio vendría a ser, de acuerdo al origen etimológico de la palabra, la casa en la que vive habitualmente la persona.

Es importante hacer una diferencia preliminar entre el domicilio de la persona física y el de la jurídica, dejando claro que el domicilio de la persona jurídica, por ser un ente de naturaleza ideal, no es el de su residencia habitual en un lugar, conforme se señala en el caso de las personas naturales en el artículo 33 del código civil peruano. Capilla (1993) refiriéndose al código civil español y a las sociedades ratifica este concepto al señalar:

Obviamente las personas jurídicas carecen de entidad física que pueda estar ubicada en lugar alguno, para constituir residencia y, así, domicilio. Por ello, la fijación de su domicilio general no puede realizarse atendiendo al criterio que según el artículo 40 del código civil señala el domicilio de las personas físicas: en su residencia habitual. (p.79-80).

Nuestro código civil en su artículo 82.1 señala lacónicamente que el estatuto de la asociación debe necesariamente contener su domicilio, lo mismo sucede en el artículo 101 para el caso de la fundación y en el 113 al referirse al comité.

Hundskopf (2008) sobre la necesidad de tener un domicilio en las sociedades, refiere a Gay de Montella, señalando:

No es concebible en el terreno jurídico comercial una sociedad de carácter internacional o apátrida, porque ningún Estado le concedería reconocimiento dentro de su territorio, y, siguiendo esta consideración, una sociedad ha de ostentar la determinación precisa de un domicilio, si no quiere ser considerada ilícita ilegal o arbitraria (p.125).

De la misma forma Álvarez (1972) respecto la necesidad de un domicilio nos señala:

Las personas morales también tienen domicilio, porque, cualquiera sea la teoría que se adopte sobre la naturaleza de las personas morales, es preciso situar al centro de sus intereses en un lugar determinado, que jugará con ella el papel de un domicilio... (571).

El código civil peruano y su inspirador o ponente, Carlos Fernández Sessarego, asumieron la posición que toda asociación debía tener o estar dotada de un estatuto, que debía constar por escritura pública y contener un conjunto mínimo de requisitos, que, en nuestro criterio, son obligatorios y de orden público, salvo algunas excepciones donde prevalece la voluntad de las partes, como ciertas normas para el funcionamiento de la Asamblea General, Consejo Directivo y otros órganos. 
Si bien el código no sanciona con nulidad el no incluir el domicilio en el estatuto, es evidente que no podría inscribirse en el Registro Público una persona jurídica que no tenga domicilio, así como gran parte de los demás requisitos obligatorios que debe contener el estatuto conforme el referido artículo 82 y demás pertinentes.

Constitucionalmente se ha planteado el derecho de constituir personas jurídicas como uno fundamental que forma parte del derecho de la libertad-libertad de asociación-, incluyendo una vertiente positiva, que contiene la facultad de auto organización y auto regulación, aunque estos derechos deben ejercerse de acuerdo, dentro o de conformidad a la ley y una vertiente negativa. Esto significa que las personas jurídicas pueden establecer libremente en su estatuto normas reglamentarias, disposiciones o pautas que la regulen con autonomía, pero con ciertos límites, fundamentalmente: la ley, el orden público y las buenas costumbres.

Los límites de la ley, por ejemplo, en el caso de asociaciones, los encontramos principalmente en el código civil en distintos artículos del mismo, especialmente en el artículo 82 de este, que prevé ciertos requisitos mandatorios que debe contener el estatuto de toda personas jurídicas asociativa, dentro de ellos, como ya se dijo, la consignación necesaria u obligatoria del domicilio por considerarse indispensable para identificar a la persona jurídica, establecer pautas mínimas para su correcto funcionamiento, poder ser correctamente notificada, así como dar garantías a los asociados y terceros, entre otros.

Hundoskpf (2008) refiere que hay códigos que han regulado los elementos que debe contener el estatuto en forma obligatoria, como es el caso del peruano, sin embargo, también señala que en otras legislaciones se plantea la posibilidad que el estatuto contenga requisitos obligatorios y optativos, precisa:

Por su parte, R. Gay de Montella señala que las normas pueden clasificarse en tres grupos: a) normas jurídicas de carácter esencial para la validez del acto constitutivo, cuya ausencia sería considerada por el Registro como defecto insubsanables para su inscripción, o que podría ser objeto de nulidad si la suscripción se hubiera efectuado teniendo en cuenta el principio de que la publicidad y la inscripción no sanean los vicios constitutivos; B) normas jurídicas facultativas, que no son de esencia para la validez del acto constitutivo y cobran vida y eficacia solamente en el caso de que los fundadores los hayan convenido y hecho constar en el estatuto; y, C) normas jurídicas, que pueden introducir los usos o costumbres mercantiles.(123).

En nuestro criterio el actual código civil peruano debió atenerse a la posición adoptada por varias legislaciones, entre ellas la italiana (Art. 16), que establece que el estatuto debe contener ciertas normas o disposiciones obligatorias, como son, claramente la denominación o el objeto, sin embargo, otras pueden ser optativas y en defecto de estas, es decir, de no incluirse expresamente en el Estatuto, la ley puede llenar estos vacíos con nomas supletorias o presunciones.

Justamente pensamos se podría aplicar esta presunción en el caso que nos atañe. Si no se pusiera el domicilio en el estatuto, la ley podría presumir que es el del lugar en donde se presenta para su inscripción, en atención al artículo 2028 el código civil, como veremos posteriormente, por lo que el registrador no debería impedir la inscripción de una asociación que en su estatuto no indique expresamente su domicilio, pero que pretenda registrase, por ejemplo, en Tacna, toda vez que al solicitar su registro en este lugar existiría una voluntad tácita de fijar domicilio en esta ciudad. Distinto es el caso del Derecho Español que señala de acuerdo a la voluntad de los asociados el 
domicilio podrá fijarse en, la sede de su órgano de representación o donde desarrolle principalmente sus actividades (Ley Orgánica 1/2002 del 22 de marzo). El estatuto, de acuerdo con la referida ley orgánica, deberá contener los siguientes extremos:

\section{Artículo.7. Los estatutos deberán contener los siguientes extremos:}

b. El domicilio, así como el ámbito territorial en el que haya de realizar principalmente sus actividades.

Agrega en su artículo $9^{\circ}$ :

Artículo 9. Las asociaciones que se constituyan con arreglo a la presente ley tendrán como domicilio en España, en el lugar en que establezcan sus estatutos, que podrá ser el de la sede de su órgano de representación, como también aquél donde desarrolle principalmente sus actividades.

$$
\text { ... }
$$

Una formula diferente presenta la Ley General de Sociedades peruana la que en su artículo 20 señala:

Artículo 20.- El domicilio de la sociedad es el lugar, señalado en el estatuto, donde desarrolla alguna de sus actividades principales o donde instala su administración. En caso de discordancia entre el domicilio de la sociedad que aparece en el Registro y el que efectivamente ha fijado, se puede considerar cualquiera de ellos. La sociedad constituida en el Perú tiene su domicilio en territorio peruano, salvo cuando su objeto social se desarrolle en el extranjero y fije su domicilio fuera del país.

En cuanto a qué se entiende por domicilio y su necesidad Sessarego (2001) menciona:

La persona jurídica, como es obvio, tiene domicilio, constituido por el lugar donde establece su sede social. Es decir, aquel donde los asociados han de desarrollar su actividad común que los agrupa y que es la causa de la constitución de la persona jurídica (p.202).

Nótese que en esta definición se asimila el concepto de domicilio al de sede social, lo que nos parece incorrecto en vista que tal como se precisará posteriormente el domicilio puede o no coincidir con la sede social, así como que las personas jurídicas pueden contar con diversas circunscripciones geográficas en donde desarrollen sus actividades debiéndose individualizar a una de ellas como su domicilio. Como se ha precisado el domicilio al ser una categoría jurídica puede no corresponder al lugar donde la persona jurídica desarrolle sus actividades.

Capilla (1993) nos refiere que el domicilio de las personas jurídicas es en realidad un domicilio legal especial de los sujetos implicados en el ente dotado de personalidad jurídica (p.80). Albaladejo (1983) lo define como: "el lugar que la ley considera como centro o sede jurídica de la persona." (p.192) y Tulia (2015) como "el atributo de la personalidad jurídica que es designado en su estatuto por el acto administrativo que le permita funcionar, considerándolo un domicilio legal "por ser el que la ley fija a los fines de ciertos efectos jurídicos" (p. 71).

Cabrejo (2015) en el mismo sentido precisa que:

Como sede legal de la persona, el domicilio general es el lugar en el cual la ley considera que ella, como sujeto jurídico, está siempre presente, aunque, de hecho, es decir, en la 
realidad, se encuentre momentáneamente alejada de él. De lo dicho resulta que el domicilio es un concepto jurídico de orden intelectivo y que su naturaleza es abstracta y ficticia. (p.158)

Para Castillo (2014) desde otro punto de vista el domicilio es entendido como el lugar donde los asociados han decidido establecer la administración (p. 403)

Podemos definir entonces el domicilio de las personas jurídicas sin fin de lucro de acuerdo a la normativa peruana como: El lugar señalado por la persona jurídica voluntariamente en el estatuto que, por mandato de la ley, es en el cual la persona se registra o inscribe, que permite ubicarla e identificarla espacialmente y en donde puede ser notificada válidamente por quienes se vinculen o necesiten vincularse con ella.

\section{3. ¿DÓNDE SE FIJA EL DOMICILIO?}

Nuestro código Civil en la sección de personas jurídicas no ha hecho referencia a dónde debería fijarse el domicilio de la asociación, por lo que se ha tenido que recurrir sistemáticamente al art.2028 de mismo código, el cual, sin lugar a dudas, prescribe que la constitución de los entes jurídicos se inscriben en el registro correspondiente a su domicilio, es decir, el Registro de Asociaciones, de Fundaciones o Comités, del Registro de Personas Jurídicas del Registro Público del lugar que señalen en el estatuto como su domicilio. Lo que es lo mismo, me domicilio donde me inscribo y me inscribo donde me domicilio.

El Reglamento de Personas Jurídicas no societarias aprobado por Resolución 038-2013-SUNARP (en adelante EI Reglamento). Fue más preciso al señalar en su en su artículo 37 qué se debe indicar al momento de fijar el domicilio:

\section{Artículo 37.- Domicilio de la persona jurídica}

En el asiento de inscripción de la constitución de la persona jurídica y en el del establecimiento de sucursal, deberá consignarse el distrito, la provincia en que domicilie y el departamento al que pertenece.

El Tribunal Registral, mediante R.2573-2016-SUNARP-TR-L de fecha 21 de diciembre del 2015 definió qué considera como domicilio, así como precisó que no era necesario consignar la dirección domiciliaria de la persona jurídica al indicar:

El domicilio de la asociación es el consignado en su estatuto social (domicilio social), el mismo que estará referido al ámbito territorial del distrito, la provincia y departamento al que pertenece, resultando irrelevante que el estatuto haya consignado la dirección determinada (con nomenclatura y numeración) de dicho domicilio social.

El mimo tribunal mediante resolución Resolución No 1341-2017-SUNARP-TR-L de Tribunal Registral de Lima, del 16-06-2017 ratificó este concepto al mencionar:

El domicilio señalado por la asociación deberá consignar el distrito, la provincia en que domicilie y el departamento al que pertenece, conforme al artículo 37 del Reglamento de Inscripciones del Registro de Personas Jurídicas, en ese sentido no procede denegar la inscripción por haberse consignado domicilio legal y no domicilio real de la asociación al momento de su constitución" 
Parece resultar claro qué es lo que se debe indicar cuando nos referimos al domicilio en el estatuto, debiendo precisarse el distrito, provincia y departamento de la asociación.

Para algunos no sería conveniente indicar la dirección domiciliaria o lugar preciso en donde tiene su sede, aunque es factible hacerlo, en vista que implicaría una modificación estatutaria cada vez que se haga una mudanza o cambio de dirección domiciliaria, lo que implicaría adicionalmente mayores costos. Asimismo, se indica que en muchos casos al momento de la constitución algunas personas jurídicas aun no cuentan con una dirección domiciliaria o local cuya dirección pudieran mencionar en su estatuto.

Al respecto se ha llegado a indicar que, por el contrario, si sería factible consignar al momento de la constitución la dirección exacta en donde la asociación tendrá su sede y que, en caso de cambio de la dirección fijada, no sería necesaria una modificación estatutaria, salvo que se cambiara de jurisdicción, es decir, distrito, provincia y departamento señalado en la dirección domiciliaria fijada en el acto constitutivo.

Es importante aclarar que nos estamos refiriendo al domicilio del ente jurídico, no de los miembros que lo conforman, en vista que en doctrina se puede afirmar que el domicilio de los asociados es el personal, sin embargo, cuando actúan como órganos o representantes sería el de la persona jurídica y allí, por ejemplo, deberían ser notificados.

\section{FUNCIONES DEL DOMICILIO.}

Se ha precisado que la necesaria fijación de un domicilio tiene importantes funciones. Sin embargo, creemos que ellas podrían diferenciarse cuando hablamos de domicilio distinto a la dirección domiciliaria. En el entendido que la dirección domiciliaria coincida con el domicilio las principales funciones de este serían:

- Contribuye al control, hasta el policial y estatal, en vista que permite verificar el espacio físico en donde desarrollan sus actividades.

- Permite la localización de su patrimonio o bienes, teniendo en cuenta que en muchos casos sus activos se ubican en su domicilio, así como su acervo documentario.

- De presunción válida de notificaciones, cuando sean efectuadas al domicilio designado para hacerle de conocimiento oficialmente de la correspondencia particular, interna o externa, administrativa y/o judicial.

- Como medio para determinar el lugar de cumplimiento de sus obligaciones. El código Civil en su artículo 1238 señala que el pago debe efectuarse en el domicilio del deudor, aclarando que en caso de cambio de domicilio (1239) se puede exigir en el domicilio antiguo o el nuevo

- Fija la competencia de los órganos jurisdiccionales, (llamado domicilio competencial) estableciendo el juez competente en un eventual caso de que deba participar en un proceso. El artículo 17 del código Procesal Civil destaca que, si se demanda a una persona jurídica, es juez competente el del domicilio donde tiene la persona jurídica su sede principal, no necesariamente su domicilio registral o legal, aclarando que, de tener varios domicilios, puede demandar en el domicilio donde ocurrió el hecho que motiva la demanda o donde sería ejecutable la pretensión reclamada.

- Permite gozar de beneficios tributarios y de diversa índole, si se fijara domicilio en zonas de frontera y selva o aquellas en donde pudieran gozar de estos beneficios incluyendo aduaneros o de otra índole que se otorguen en función al domicilio señalado. 
- Es un medio para asignar la nacionalidad a las personas jurídicas, aun en aquellos casos en la cual se niega la nacionalidad a las personas jurídicas y más bien se habla de personas domiciliadas y no domiciliadas. De la misma forma un conector que permite establecer la competencia territorial en caso de la aplicación del derecho internacional privado, como cuando el artículo 2057 del código civil, precisa que los tribunales peruanos son competentes para conocer de las acciones contra personas domiciliadas en el territorio nacional.

- Tiene función identificadora importante al poderla localizar en un determinado sitio y diferenciarla de otra, que es el caso de aquellas que pudieran tener una denominación y actividad similar o igual.

- Es el lugar de las publicaciones que deban efectuarse en el caso que la ley o el estatuto lo requiera, de acuerdo a la ley de sociedades,

- El lugar donde en principio deben sesionar sus órganos, salvo pacto en contrario.

El Artículo 52 del Reglamento de personas jurídicas no societarias señala:

Para efectos registrales es válida la sesión del órgano colegiado realizada en cualquier lugar del ámbito territorial del domicilio de la Persona jurídica, salvo disposición legal o estatutaria diferente.

- Constituye el lugar de cumplimiento de obligaciones fiscales y administrativas.

De Castro y Bravo (1984) resume la importancia del domicilio en la persona jurídica al referir:

Ha de ser el centro de la vida social; será el que se señale el registro correspondiente donde ha de constar su inscripción. (publicidad) determinará en muchos casos la competencia y jurisdicción de los tribunales y puede ser tenida en cuenta para determinar la nacionalidad (p.288).

\section{HABITACIÓN, RESIDENCIA, PARADERO, DOMICILIO, DIRECCIÓN DOMICILARIA Y LA SEDE SOCIAL.}

La habitación es el edificio, casa, y cualquier otra construcción o lugar natural que se emplea para vivir.

Hablamos de residencia cuando hay un ánimo de permanencia de la que carece la primera.

El paradero es el lugar exacto en donde circunstancialmente se encuentra la persona accidental o temporalmente.

Estos tres conceptos son propios de la persona natural, no siendo aplicables a la persona jurídica, que más bien tiene domicilio, sede social o dirección domiciliaria.

En nuestro criterio dirección domiciliaria será la dirección exacta y precisa de una residencia, vivienda o inmueble en particular; en tanto, domicilio es uno legal en donde me registro para efectos legales, de modo tal que el domicilio es mucho más amplio que la simple dirección domiciliaria, puesto que la contiene.

No es lo mismo domicilio, sede social, que dirección domiciliaria. Espinoza (2012) aclara la distinción respecto de la dirección domiciliaria a la cual él llama dirección o sede social al detallar: 
Nótese que no debe confundirse domicilio con dirección, la cual ha de constar en otros documentos de la persona jurídica (ejemplo el formulario para obtener el RUC) A nivel de la doctrina nacional, se distingue sede social. Así, "el domicilio de la persona jurídica se determina en relación a una circunscripción territorial, en cuyo registro público se ha inscrito esta. En cambio, la sede social es el lugar fijo y específico en el que la sociedad realiza alguna de sus actividades fijando su administración (p. 269-270).

Beaumont (1998) diferencia entre domicilio social y dirección de la siguiente forma:

... No se debe confundir el domicilio con la dirección. El domicilio es la zona geográfica, ciudad, provincia, que sirve de lugar de instalación y ubicación- de una sociedad y ordinariamente de la empresa de la que ella es titular. (p.93).

En cuanto al concepto de sede social puede coincidir o no con el domicilio legal, pudiendo existir una sede principal y otras secundarias o alternas, pero solo un domicilio legal, que de acuerdo a ley es el fijado en el estatuto y donde me registro, como ya se dijo o el que señale la ley.

Elías (1998) distingue bien entre domicilio social y sede social, anotando que:

... la sede social será el lugar fijo y específico en el que la sociedad puede realizar alguna de sus actividades o fijar su administración, mientras que el domicilio será una circunscripción territorial en cuyo registro público deba inscribirse la sociedad (p.60).

En el ya mencionado pleno Quilpe en la argentina se mencionó:

Pareciera obvio repetir que los conceptos de sede y domicilio no tiene un unívoco significado en nuestro derecho positivo Es decir: el domicilio es el lugar en el cual la ley ubica al sujeto de derecho para el cumplimiento de sus obligaciones (conf. García Cáffaro, José L., "¿Mención del domicilio o especificación de la sede social en contratos o estatutos?", en Rev. LA LEY, t. 152, p. 409). Y la sede, puede coincidir con aquél o no, pero su conceptuación es de tipo fáctica; lugar desde donde se dirige a la sociedad, donde deliberan sus órganos de dirección y gobierno, donde se forma -en síntesis- la real voluntad societaria. En la ley de sociedades se patentiza la diferencia respecto de las sociedades constituidas en el extranjero (arts. 118 y 124).

Esta diferenciación de sede y domicilio la encontramos también en el código civil y comercial argentino el que en su artículo 152 precisa esta distinción al mencionar:

Artículo 152. Domicilio y sede social El domicilio de la persona jurídica es el fijado en sus estatutos o en la autorización que se le dio para funcionar. La persona jurídica que posee muchos establecimientos o sucursales tiene su domicilio especial en el lugar de dichos establecimientos sólo para la ejecución de las obligaciones allí contraídas. El cambio de domicilio requiere modificación del estatuto. El cambio de sede, si no forma parte del estatuto, puede ser resuelto por el órgano de administración.

Veamos un ejemplo concreto; el Touring Automóvil Club del Perú es una asociación civil, su domicilio estatutario es donde se inscribió: Distrito de Lince, Provincia de Lima, Departamento de Lima. Su dirección domiciliaria es Av. Trinidad y Morán N698, Lince y tiene varias sedes. La principal en Lince ya acotada (coincidente con la dirección domiciliaria) y otras en la panamericana sur y provincias como: Trujillo, Arequipa, Piura, etc. 
Domicilio, dirección y sede pueden coincidir o no, es decir, que puedo domiciliar en Lima, tener mi sede en Ica y varias direcciones para determinados efectos.

Otro ejemplo interesante puede ser el de un club de playa ubicado en el sur de Lima, cuya inscripción y domicilio puede estar Lima, su sede física o club social en Cañete y su dirección domiciliaria en una oficina especialmente fijada en Lima, para que los asociados tengan un lugar donde a dejar o recibir correspondencia o efectuar trámites en la temporada de invierno, por cuando la mayoría de asociados residen permanentemente en Lima.

\section{EL DOMICILIO DE LA PERSONA JURÍDICA EN NUESTRO CÓDIGO CIVIL}

Resulta interesante preguntarse si nuestro código civil ha regulado adecuadamente el domicilio de la asociación, fundación y comité, así como si ha distinguido claramente sede de domicilio.

\subsection{DOMICILIO DE LA ASOCIACIÓN.}

El artículo 82.1 del código peruano señala taxativamente, que la asociación debe tener un domicilio, debiéndose entender como el lugar donde se inscribirá, así como en su designación bastará indicar el Distrito, Provincia y Departamento en donde se desea domiciliar.

No se ha definido el domicilio ni diferenciado de la sede social.

El código, para efectos procesales en los artículos 85 y 92 ha indicado que la convocatoria judicial a asamblea de asociados y las demandas de impugnación de acuerdos se presentarán en el lugar del domicilio de la persona jurídica referencia concreta para fijar la competencia de los órganos jurisdiccionales de conformidad con el código Procesal Civil. Sin embargo, el artículo 17 del referido código procesal señala: "si se demanda a una persona jurídica, es competente el juez del domicilio en donde tiene su sede principal, salvo disposición legal en contrario." ...

Por lo expuesto en estos artículos comentados más que a domicilio para ser concordante con la legislación procesal debió referirse a domicilio en que se encuentra su sede principal.

El artículo 98 del código civil, hace referencia al destino del haber neto resultante luego del proceso de disolución y liquidación de la asociación en caso no sea posible su entrega a los designados en el estatuto. En este caso se dispone que la Corte Superior dispone su aplicación afine análogosdebiéndose entender a actividades u objetivos - similares en interés de la comunidad, "dando preferencia a la provincia donde tuvo sede la asociación".

La pregunta que vale la pena formularnos es si el cambio en la referencia de domicilio a sede tiene algún sustento a simplemente se trataría de palabras sinónimas

Como se mencionó el Dr. Fernández Sessarego (p.9) al definir domicilio los considera como la sede social, ha considerado ambos conceptos como semejantes. No encontramos argumentos de fondos suficientes para sustentar el cambio de referencia a sede, pudiéndose haber indicado "dándose preferencia la provincia donde la asociación tuvo su último domicilio", lo que es más coherente si hemos indicado que, domicilio se refiere más que a una dirección o sede exacta al distrito o provincia y departamento fijado en el estatuto. 


\subsection{DOMICILIO DE LA FUNDACIÓN.}

De conformidad con el artículo 101 del código civil la fundación puede incluir su domicilio en el acto constitutivo, de no hacerlo el Consejo de Supervigilancia de Fundaciones lo determinará necesariamente a tenor de lo dispuesto en el artículo 104.

El artículo 109 refiere a la demanda de disolución en caso la finalidad devenga de imposible cumplimento, precisando que la misma debe ser planteada ante el juez civil de la sede de la fundación. Esta precisión no es coherente con lo señalado en el caso de las asociaciones que refieren al domicilio como factor determinante para fijar la competencia de los jueces. Donde habría la misma razón debería haber el mismo derecho.

Finalmente, en cuanto al destino del haber neto resultante de la fundación, el artículo 110 del código civil ha seguido el mismo criterio que el art. 98 del mismo cuerpo normativo ya comentado, disponiendo que deberá ser entregado, en caso no ser posible aplicarlo a la finalidad propuesta a otra fundación de similares propósitos a los que tenía la fundación en la localidad donde tuvo su sede. Nótese que no se refiere a provincia sino a localidad, concepto vago e impreciso. Lo comentado respecto del artículo 98 es plenamente aplicable a este artículo.

\subsection{DOMICILIO DE COMITÉ}

El estatuto de comité al igual que el de la asociación, de conformidad con el artículo 113.1 del código civil debe indicar el domicilio.

El artículo $122 \mathrm{~L}$ referirse al destino del haber neto resultante menciona que debe entregarse a la beneficencia pública del lugar, no siguiéndose la técnica legislativa de la asociación y fundación en donde se menciona a la sede. Las Beneficencias Públicas de conformidad con la ley de la materia, Decreto Legislativo $\mathrm{N}^{\circ} 1411$, tiene circunscripción territorial provincial, por lo que habría sido más correcto señalar la beneficencia correspondiente a la provincia donde domicilia la o si se quiere tenga su sede el comité. Asimismo, se podría plantear la beneficencia del lugar en donde el comité esté desarrollando sus actividades altruistas principales.

\subsection{DOMICILIO DE LA FUNDACIÓN NO INSCRITA}

Resulta curiosa la formula señalada en el artículo 129 del código civil referida a las fundaciones no inscritas, las que, de acuerdo a esta norma, deberán afectar sus bienes, en caso no logren inscribirse a otra fundación preferentemente establecida en el mismo distrito judicial.

Ya no se refiere a domicilio, sede, ni lugar ahora, se introduce una categoría por demás extraña, distrito judicial.

En nuestro criterio debería entregarse a una fundación domiciliada en la zona o lugar en donde la fundación planificó desarrollar sus actividades de interés social y en su defecto en el lugar de su domicilio, en el entendido que al no estar constituidas es muy probable no tenga sede social.

\section{LA PROTECCIÓN CONSTITUCIONAL DEL DOMICILIO}

Nuestro Tribunal Constitucional en el Expediente 2389-2009-PA/TC dejó sentada su posición respecto a qué considera como domicilio y su protección constitucional. 
El caso se centra en que el gobierno expidió el Decreto Supremo 023-2008-PC que permitía el acceso del público en general a los centros de esparcimiento, recreación y cultura construidos sobre predios del Estado. La asociación privada Club Petro Perú, planteó una acción de garantías constitucionales para que no se les aplique la norma, en el entendido que, si bien recibieron un terreno del Estado, en este construyeron, con fondos propios de sus asociados, su sede social y por ende permitir el ingreso a terceros implicaba violar su domicilio, inclusive no permitiría aplicar las normas internas de la asociación a personas que ingresen y no fueran asociados, como el caso de sanciones.

El Tribunal consideró que la persona jurídica goza de ciertos derechos fundamentales aplicables a la persona natural, (salvo los derechos llamados personalísimos o inherentes a la persona humana) dentro de ellos la inviolabilidad de su domicilio. Señaló como domicilio en general, el ámbito de privacidad que la propia persona elije para él y su familia y se caracteriza por ser inmune a la injerencia y las presiones o ataques de otros privados o de alguna autoridad. Precisó que es evidente que el derecho al domicilio solo le puede corresponder a un sujeto jurídico y como queda claro, una asociación es una persona jurídica; y por ende un sujeto de derechos, en consecuencia, el derecho al domicilio e inviolabilidad le es aplicable. Agregó: "Entonces, partiendo de lo dicho anteriormente, es comprensible, que las personas jurídicas también puedan ser titulares del derecho a la inviolabilidad del domicilio porque cuentan con un espacio más o menos amplio donde despliegan las actividades propias y contiguas a su objeto social."

Expresa que la inviolabilidad del domicilio es un derecho negativo considerado en el caso de la persona jurídica como el centro de su vida social, lo que determina su jurisdicción, tribunales y hasta nacionalidad.

Lo más importante es que considera que para las personas jurídicas el concepto constitucional de domicilio es más amplio ya que protege el recinto, móvil o inmóvil o de uso transitorio o accidental, así como todos los espacios cerrados donde la persona jurídica desarrolla su intimidad y personalidad separada de terceros. Aclara que en el ámbito constitucional se protege no solo la sede social, sino el lugar o lugares en donde la persona jurídica desarrolla sus actividades cotidianas.

Con lo dicho, queda claro que el domicilio del club Petroperú, se encuentra localizado en la Ciudad de Lima, pero adicionalmente cuenta con una dirección domiciliaria a la que, por cierto, le son aplicables las mismas connotaciones del domicilio en general. Por lo tanto, la dirección exacta y sede donde se ubicaba el inmueble y donde el citado club desarrolla las actividades de sus integrantes también es susceptible de protección, añadiendo que: nadie podrá ingresar a las instalaciones ubicadas en Av. El Golf, ni efectuar investigaciones ni registros en él, si no cuenta con la autorización de los asociados, salvo por mandato judicial.

Se redondea el fundamento aseverando que el local no solamente constituye el domicilio (en sentido restringido) constitucional del club Petroperú, sino también el de sus asociados, cuando se encuentran dentro de él, por lo que se está impidiendo que tanto los asociados como el club se interrelacionen exclusivamente entre ellos.

En consecuencia, el Tribunal declaró inaplicable la norma a la asociación, ente privado, autónomo que había construido su sede, como se dijo, con dinero que no provenían del erario público.

En similar sentido, el Tribunal Constitucional español interpretó en STC 22/1984, de 17 de febrero, que el domicilio al que hace referencia el artículo 18 de su constitución es un concepto más amplio que el establecido en el Derecho Privado o en el Derecho Administrativo. Según la citada sentencia: 
En relación con este tema debe señalarse que la idea de domicilio que utiliza el artículo 18 de la Constitución no coincide plenamente con la que se utiliza en materia de Derecho privado (...). La protección constitucional del domicilio es una protección de carácter instrumental que defiende los ámbitos en que se desarrolla la vida privada de la persona. Por ello existe un nexo de unión indisoluble entre la norma que prohíbe la entrada y el registro en un domicilio, artículo 18.2 de la Constitución, y la que impone la defensa y garantía del ámbito de la privacidad. Todo ello obliga a mantener por lo menos "prima facie" un concepto constitucional de domicilio de mayor amplitud que el concepto jurídico-privado o jurídico-administrativo (FJ 2. ${ }^{\circ}$ ).

De otro lado la sentencia del tribunal español 137/1985 aclaró que el derecho de negativo a la inviolabilidad del domicilio también es aplicable a las personas jurídicas al mencionar:

El concepto de domicilio constitucionalmente protegido se extiende al de las personas jurídicas y por ende en mi opinión al domicilio profesional o empresarial y no sólo al domicilio particular, así lo refleja también el art. 91 de la LOPJ. Es decir, que habiendo unanimidad en la doctrina y en la jurisprudencia acerca de la protección de la inviolabilidad del domicilio de las personas jurídicas, que por su propia naturaleza puede revestir la forma de finca, local, establecimiento o lugar donde se desarrolla una actividad profesional o empresarial, no es posible entender en una interpretación acorde con el concepto constitucional de domicilio, que cuando estos pertenecen a una persona física no requieran la autorización judicial.

En España también, la sentencia del TC 211-11-del 87 indicó que la protección al domicilio es igual a personas naturales o jurídicas, las que tienen derecho a la vida privada. Dejando claro que esto no ocurre cuando los funcionarios judiciales o administrativos actúen de acuerdo a mandatos de entrada y registro expedido por los juzgados correspondientes.

Finalmente se precisó que la protección del domicilio en cuanto su inviolabilidad procede para proteger la intimidad de la persona que es aplicable también a la persona jurídica, indicando: "tiene derecho a controlar la información sobre sí misma que le impida o dificulte la consecución del fin colectivo y permanente para el cual se creó".

\section{TIPOS DE DOMICILIO}

Podemos hablar de distintos tipos de domicilio como:

8.1. El fijado por ley o legal, para determinado tipo de actividades que es de carácter mandatorio u obligatorio.

Es el lugar donde la ley presume, sin admitir prueba en contra, que la persona jurídica domicilia para el ejercicio de sus derechos y el cumplimiento de sus obligaciones, aunque podría no ser el real.

Este domicilio es forzoso, en cuanto lo impone la ley independientemente de la voluntad del interesado y en el Perú es el lugar donde la persona jurídica decidió registrase y fijar el Distrito, Provincia y Departamento en donde se afincará para efectos legales y es establecido en el acto constitutivo y/o sus modificaciones. También podría ser legal si la ley lo determina para alguna circunstancia, como el caso del Municipal, para el pago de algún tributo. 
8.2 El voluntario o el pactado, puede ser establecido en su fundación o acto constitutivo en forma libre o voluntaria, convenirse entre las partes para un determinado negocio o actividad, así como como puede ser el fijado con una entidad prestadora de servicios básicos, como la luz o el servicio telefónico.

8.3 El principal y secundario(s), en el primero realiza la persona jurídica su actividad principal o más importante, a diferencia de agencias, sucursales y otras oficinas en donde pueda desarrollar actividades secundarias.

8.4 El tributario, que es el comunicado a la entidad tributaria y se fija al solicitar el Registro Único Tributario- RUC, llamado también fiscal, que conecta al acreedor tributario con el deudor tributario. Por lo general hay un domicilio fiscal, pero podrían fijarse varios para recibir acotaciones o multas notificadas en distintos, distintos al fiscal.

En principio el domicilio fiscal puede variarse salvo cuando deba ser autorizado por la SUNAT, lo que puede ocurrir si se encuentra en proceso de fiscalización o verificación, dentro otros motivos señalados en el código Tributario.

8.5 El general y específico, el general es el lugar que la ley estima como sede social donde actúa generalmente la persona y los especiales son los fijados para la realización de ciertos actos como el administrativo, fiscal o laboral.

8.6 El internacional, para entidades que operan en el comercio Internacional y pudieran tener un domicilio nacional y otro u otros en el extranjero.

8.7 El real, es aquel en donde efectivamente la persona jurídica desarrolla sus actividades cotidianas.

8.8 El electrónico, se ha planteado, que, en atención al advenimiento de la tecnología, de la comunicación online o en línea y más aun con el desarrollo de las comunicaciones por esta vía en virtud del COVID 19, podrían las personas jurídicas junto con el domicilio legal, en el momento de su constitución fijar uno electrónico que debería inscribirse inclusive en el registro público, que permitiría una notificación y comunicaciones más eficientes, rápidas y acordes con la realidad actual.

\section{CARACTERÍSTICAS DEL DOMICILIO.}

Son características del domicilio las siguientes:

- No cambia, salvo cuando hay un acuerdo de los miembros de las personas jurídicas, lo que implica una modificación estatutaria y su nueva inscripción. Si el domicilio no fuera de la circunscripción inicial convenida, es necesario un trámite registral que permita cerrar la partida original de inscripción y trasladar los antecedentes al registro del nuevo domicilio

- Es necesario, es ineludible que se cuente con un domicilio

- Plural, pueden existir varios, aunque solo uno es el domicilio legal, el estatutario.

- Es voluntario, en el sentido que corresponde a los asociados fijarlo de acuerdo a sus propios deseos y conveniencias, salvo cuando existan exigencias de orden legal que presume la existencia de un domicilio legal.

- Es inviolable, salvo las excepciones previstas en la legislación.

- Es único, refiriéndose al domicilio legal. La Resolución No. -117-2012 -SUNARP-TR- 
Lima, de noviembre del 2012, indicó la imposibilidad que una asociación cuente con dos domicilios, uno en Lima y otro en el callao, al respecto señaló:

Es por ello que, siendo el acto bajo evaluación una modificación del estatuto, debemos verificar que en el estatuto cuya inscripción se solicita no se haya estipulado la pluralidad de domicilios.

Apreciamos que el artículo 2 del estatuto contenido en la escritura del 28/5/2012 señala:

El domicilio del Club Distrital Punta de Bombón es la Ciudad de Lima MetropolitanaCallao. Su sede institucional está ubicada en su local propio de la calle Francisco Sarmiento de Gamboa \#102 Urb. La Colonial - Callao-

Consecuentemente, al advertirse la misma situación, no podrá inscribirse dicha modificación del estatuto, siendo el mismo un defecto subsanable, puesto que mediante sesión posterior podrá definirse como domicilio de la asociación a una sola provincia, sin perjuicio que dicho estatuto pueda establecer que las sesiones se realicen en lugar distinto al domicilio.

\section{LEGISLACIÓN COMPARADA.}

Ya se han señalado las normas que regulan la necesaria designación del domicilio en Perú, así como las que de otra forma lo regulan en Argentina y España.

- En Chile se establece que toda asociación deberá designar un domicilio en su estatuto, conforme al artículo 548.2 del código civil; la Ley 20550;

- En Colombia el Decreto 1529 en su artículo 3.b exige que la asociación deba señalar un domicilio; aunque para su reconocimiento se requiere designar su domicilio y dirección.

- En Brasil, se habla más bien de sede en los artículos 46 y 54.1 del código civil, que deberá constar expresamente en el estatuto social.

- En Méxicoel artícluo 33 del código civil federal refiriéndose a la persona moral señala: Las personas morales tienen su domicilio en el lugar donde se halle establecida su administración. Las que tengan su administración fuera del Distrito Federal pero que ejecuten actos jurídicos dentro de su circunscripción, se considerarán domiciliadas en este lugar, en cuanto a todo lo que a esos actos se refiera. Las sucursales que operen en lugares distintos de donde radica la casa matriz, tendrán su domicilio en esos lugares para el cumplimiento de las obligaciones contraídas por las mismas sucursales. los artículos 2671 -2673 nos hablan de domicilio.

- En Costa Rica La Ley 218 (7.2) prescribe la designación necesaria también de un domicilio.

- Código civil de Nueva León. (art.29) precisa que el domicilio de las personas morales se determina:

I. Por la ley que las haya creado o reconocido o las leyes que las fija directamente;

II. Por su escritura de constitutiva, los estatutos sociales; y

III. En defecto de lo anterior donde se halle establecido su administración o se encuentre su representante legal.

- El Código civil italiano menciona que el acto constitutivo de la persona jurídica debe contener la sede. 


\section{CONCLUSIONES.}

1. El Código civil peruano debe consignar una definición de domicilio de la persona jurídica y establecer claramente la diferencia con la sede social.

2. En caso que una persona jurídica sin fines de lucro no consigne su domicilio se podría presumir como tal el Distrito, Provincia y Departamento en donde se presenta para su inscripción en el registro.

3. El Código ha utilizado distintas denominaciones para referirse al domicilio: sede, lugar y hasta distrito judicial; no pudiéndose establecer claramente si ha utilizado dichas denominaciones como conceptos sinónimos o conceptos distintos, lo que requiere una profunda revisión y modificaciones legislativas a fin de unificar criterios y denominaciones tanto para las asociaciones, fundaciones como para los comités.

\section{REFERENCIAS}

- Albaladejo, M. (1983). Curso de Derecho civil español I- Introducción y parte general. Bosh.

- Álvarez R. (1972). El domicilio. Revista anuario de derecho civil Vol.25, N². Agencia estatal Boletín oficial del Estado.

- Beaumont, R. (1998). Ley general de sociedades. Gaceta Jurídica.

- Cabrejo, N. (2015) Código Civil Peruano Treinta años después luces y sombras sobre el domicilio. En Revista Vox Juris (29). Universidad San Martín de Porres.

- Capilla, F. (1993). La persona jurídica funciones y disfunciones. Tecnos.

- Castillo, G. (2014). Código Civil Comentado, Tomo I. Gaceta Jurídica.

- Cifuentes. S (1991) Elementos de derecho civil. Edit. Astrea.

- Domínguez, M. (2009). Los Atributos de la persona. Revista Venezolana de jurisprudencia.

- Elías, E. (2012) Derecho de las Personas. Grijley.

- Fernández Sessarego, C. (2001). Derecho de las Personas -Exposición de motivos y comentarios del Código Civil Peruano. Grijley.

- Hundskopf, E. (2008). Derecho Comercial, en Temas societarios Tomo VIII. Universidad de Lima.

- Salas, J. (1979). Sociedades Reguladas por la Ley General de Sociedades. PUCP.

- Treviño, R. (2002). La persona jurídica y sus atributos. Universidad Autónoma de Nuevo León.

- Tulia, M. (2015). Personas Jurídicas asociaciones civiles fundaciones en el nuevo código civil y comercial. Ediciones Jurídicas.

Fecha de recepción : 29 de octubre de 2021

Fecha de aceptación: 21 de noviembre de 2021 